\title{
Editorial
}

\section{Water: Analysis, Treatment, and Reuse}

\author{
Ghadir A. El-Chaghaby, ${ }^{1}$ Nour T. Abdel-Ghani, ${ }^{2}$ \\ Mohd Rafatullah, ${ }^{3}$ and José Morillo Aguado ${ }^{4}$ \\ ${ }^{1}$ Agricultural Research Center, Giza, Egypt \\ ${ }^{2}$ Cairo University, Giza, Egypt \\ ${ }^{3}$ Universiti Sains Malaysia, Penang, Malaysia \\ ${ }^{4}$ University of Seville, Seville, Spain \\ Correspondence should be addressed to Ghadir A. El-Chaghaby; ghadiraly@yahoo.com
}

Received 5 August 2015; Accepted 5 August 2015

Copyright (C) 2015 Ghadir A. El-Chaghaby et al. This is an open access article distributed under the Creative Commons Attribution License, which permits unrestricted use, distribution, and reproduction in any medium, provided the original work is properly cited.

Water quality is an important issue and its degradation is a major threat for everyone. A large quantity of water is wasted as wastewater arising from several activities such as industrial, and agricultural. The environmental pollution arising from the discharge of untreated wastewater is increasing and the quest for finding different water treatment methods is highly encouraged.

In this special issue, we aimed to gather recent researches concerned with water analysis and new developed methods and materials used for water decontamination. Our special issue contains six relevant research articles for authors from Hungary, Zimbabwe, China, Spain, Korea, and India.

The article authored by A. Szekacs et al. is a survey monitoring pesticide residues in surface and ground water in Hungary. In this survey, more than two thousand water samples have been analyzed and the effects of pesticide contamination on ecological farming and drinking water supply have been assessed. In this special issue, F. Chigondo et al. investigated the extraction of alum (a coagulant that is used for raw water treatment) from locally abundant kaolin clays using sulphuric acid. Also, J. Yang et al. reported their successful results for establishing a three-dimensional model integrating computational fluid dynamics (CFD) and biokinetics to model an expanded granular sludge bed reactor. The article by $\mathrm{T}$. Llano et al. describes the evolution of lignin, sugars, and other decomposition products derived from hemicelluloses and cellulose in a sulfite pulp mill. $\mathrm{H}$. Lade et al. reported the use of Providencia rettgeri strain HSL1 as a low-cost growth medium for the enrichment of bacteria and their further use for biodegradation of azo dye and its derivatives containing wastes into nontoxic form. And the article authored by $\mathrm{Z}$. Jing et al. described the degradation characteristics of aniline during ozonation.

\section{Acknowledgments}

Finally, the guest editors wish to express their thanks to all those who have contributed to this special issue, especially the authors and the reviewers of the articles. They thank the editorial staff of the journal for their help in managing the issue.

\author{
Ghadir A. El-Chaghaby \\ Nour T. Abdel-Ghani \\ Mohd Rafatullah \\ José Morillo Aguado
}



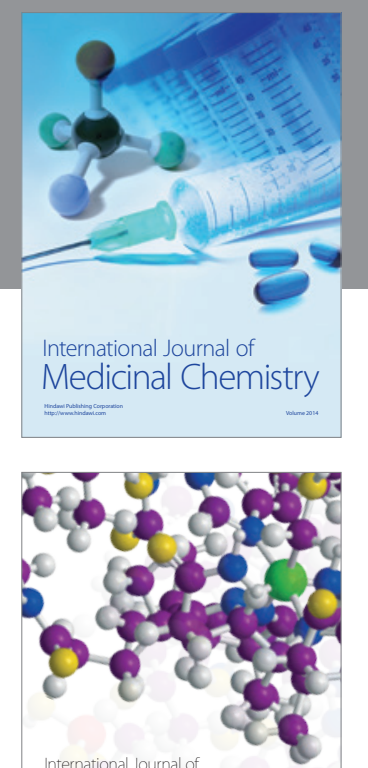

\section{Carbohydrate} Chemistry

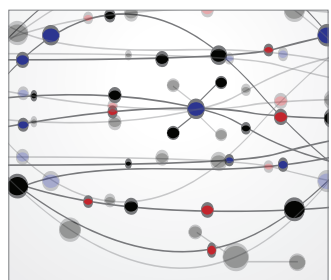

The Scientific World Journal
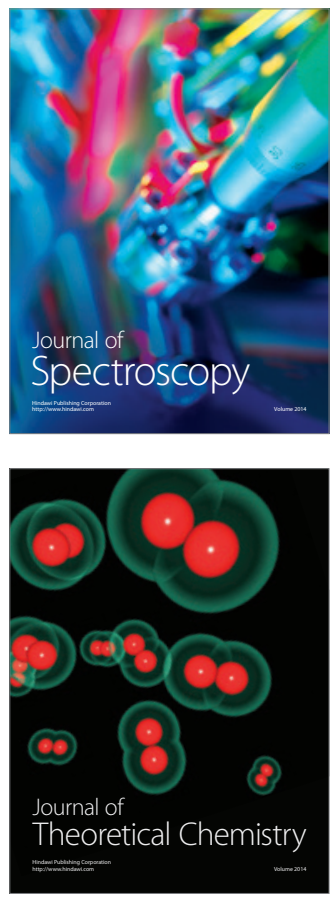
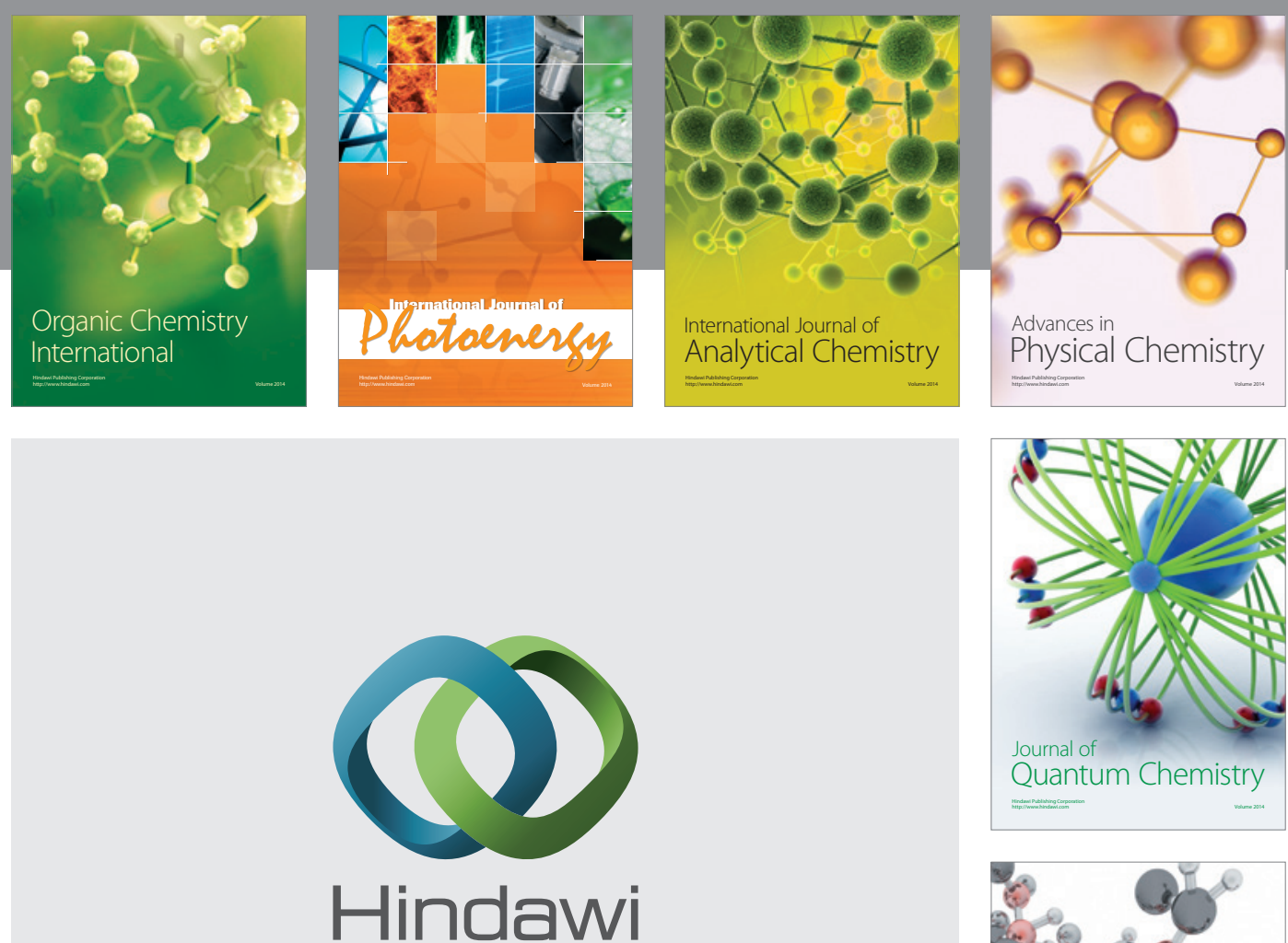

Submit your manuscripts at

http://www.hindawi.com

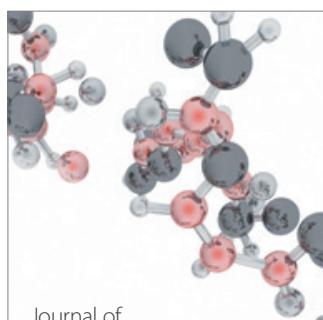

Analytical Methods

in Chemistry

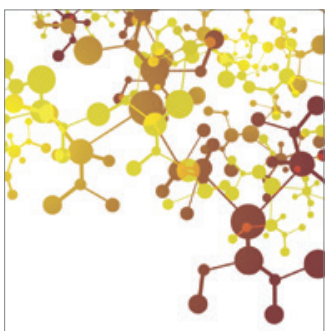

Journal of

Applied Chemistry

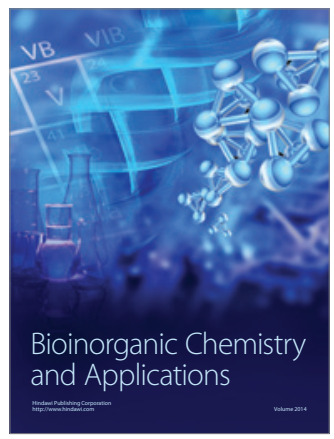

Inorganic Chemistry
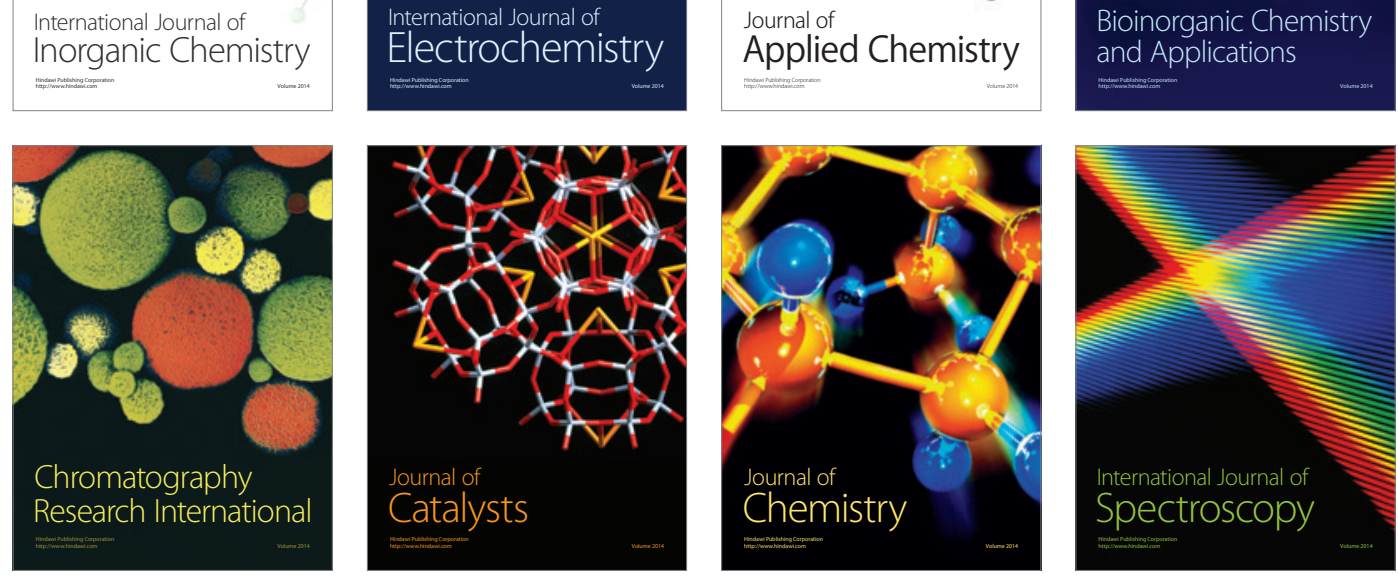